\title{
Alfabetização de surdos: para além do alfa e do beta
}

\author{
Isaac Figueredo de Freitas' (D)
}

\section{RESUMO}

Este artigo objetiva discutir teoricamente, em tom de síntese, a natureza da alfabetização de surdos em duas vertentes: a alfabetização em Língua Brasileira de Sinais (Libras), por meio do sistema de escrita SignWriting, e em língua portuguesa, pelo sistema alfabético-ortográfico latino. $\mathrm{O}$ texto pontua as especificidades de cada modalidade de alfabetização e discute as problemáticas que do ponto de vista do autor apresentam-se com maior saliência no cenário educacional brasileiro atual. O trabalho defende que a alfabetização de surdos em Libras seja contemplada também pela escrita de sinais, mediante o sistema SignWriting, e aponta a necessidade de políticas linguísticas que sistematizem e legitimem essa proposta. Ademais, propõe premissas aos alfabetizadores de surdos que ensinam a língua portuguesa escrita como segunda língua.

PALAVRAS-CHAVE

alfabetização em Libras; ensino de português para surdos; sistema SignWriting.

'Universidade Federal do Vale do São Francisco, Senhor do Bonfim, BA, Brasil. 


\section{LITERACY FOR THE DEAF: BEYOND ALPHA AND BETA}

\section{ABSTRACT}

This paper aims to theoretically and synthetically discuss the nature of literacy for the deaf through two approaches, namely: literacy in Brazilian Sign Language (Lingua Brasileira de Sinais - Libras), using the SignWriting system; and literacy in Portuguese, through the Latin alphabet alphabetic-orthographic system. This text indicates the specificities of each literacy method and discusses the more prominent problems, as perceived by the author, in the current Brazilian educational scenario. The paper argues that literacy for the deaf in Libras must be addressed by teaching methods for writing sign language through the SignWriting system, and points out the need for linguistic policies that systematize and legitimize this proposal. Furthermore, it proposes premises for those teaching literacy to the deaf who teach written Portuguese as a second language.

\section{KEYWORDS}

literacy in Brazilian Sign Language (Libras); teaching Portuguese to the deaf; SignWriting system.

\section{ALFABETIZACIÓN DE SORDOS: MÁS ALLÁ DEL ALFA Y DEL BETA}

\section{RESUMEN}

Este artículo objetiva discutir teóricamente, en tono de síntesis, la naturaleza de la alfabetización de sordos en dos vertientes, a saber: la alfabetización en Lengua de Signos Brasileña (Lingua Brasileira de Sinais - Libras), a través del sistema de escritura SignWriting; y en portugués, a través del sistema alfabético-ortográfico latino. El texto señala las especificidades de cada modalidad de alfabetización y debate sobre las problemáticas que, para el autor, tienen mayor prominencia en el escenario actual educativo brasileño. El trabajo defiende que la alfabetización de sordos en Libras, sea contemplada por la enseñanza de la escritura de señas con el SignWriting y apunta a la necesidad de políticas lingüísticas que sistematicen y legitimen esta propuesta. Además, propone premisas a los alfabetizadores de sordos que enseñan la lengua portuguesa escrita como segunda lengua.

\section{PALABRAS CLAVE}

alfabetización en Lengua de Signos Brasileña (Libras); enseñanza de portugués para sordos; sistema SignWriting. 


\section{INTRODUÇÃO}

Reencontrar o mundo dos surdos é um verdadeiro alivio. Deixar de fazer esforços. Não precisar me estafar na tentativa de falar oralmente. Reencontrar as mãos, o à vontade, os gestos que voam, que falam sem esforço, sem constrangimento. O movimento do corpo, a expressão dos olhos, que falam. De súbito desaparecem as frustraçôes. Laborit, 2000, p. 133

Estudos em torno do ensino e da aprendizagem da língua portuguesa escrita para/por crianças surdas não são novidade no cenário brasileiro. Sem a pretensão de esgotar a lista, alguns desses estudos são apresentados, a seguir, em ordem cronológica: Gesueli (1988); Costa (2001); Dechandt-Brochado (2003); Salles et al. (2004a, 2004b); Dechandt-Brochado (2006); Quadros e Schmiedt (2006); Pires e Lopes (2007); Salles, Salles e Chan-Viana (2007); Finau (2007); Karnopp e Pereira (2012); Karnopp (2012); Pereira (2012); Gesueli (2012); e Ribeiro (2013).

De menor volume, entretanto, são os estudos sobre o ensino e a aprendizagem da escrita de sinais para/por crianças surdas pelo sistema de escrita SignWriting. No Brasil, destaca-se o trabalho pioneiro de Stumpf (2005), em formato de tese acadêmica, intitulado: Aprendizagem de escrita de lingua de sinais pelo sistema SignWriting: linguas de sinais no papel e no computador. Somam-se a essa pesquisa seminal outros estudos e publicações relacionados ao ensino e à aprendizagem da escrita de sinais, apresentados aqui também em ordem cronológica: Loureiro (2004); Denardi (2006); Barth (2008); Silva (2009); Zappe (2010); Nobre (2011); Dallan (2012); Wanderley (2012); Silva (2013); Almeida (2015); Bózoli (2015); Barreto e Barreto (2015); Kogut (2015), entre outros.

Ante o significativo número de estudos então realizados, em uma tentativa de não tematizar sobre o que já recebeu tratamento teórico, este artigo, em tom de síntese, tem como proposta central produzir uma discussão teórica em torno da natureza da alfabetização em Língua Brasileira de Sinais (Libras) por meio do sistema de escrita SignWriting - conjunto sistemático de unidades gráficas que possibilita o registro direto de qualquer língua de sinais - e em língua portuguesa, que toma como ferramenta de registro o sistema alfabético-ortográfico latino, também utilizado para o registro grafêmico de outras línguas orais ao redor do mundo.

Com esse propósito em mente, o artigo encontra-se divido em quatro seções temáticas que apresentam o seguinte roteiro de conteúdo:

1. a alfabetização de surdos em Libras e as especificidades do sistema SignWriting em relação ao sistema alfabético-ortográfico latino;

2. a alfabetização de surdos em língua portuguesa e algumas premissas para os alfabetizadores de surdos;

3. as problemáticas que subjazem a alfabetização de surdos tanto em Libras como em língua portuguesa, tomadas as especificidades de cada língua; e, por fim;

4. as considerações finais do autor. 


\section{ALFABETIZAÇÃO DE SURDOS EM LIBRAS}

Quando se fala em alfabetização de surdos, tomando alfabetização como "a aprendizagem do sistema alfabético-ortográfico, que conduz à habilidade de leitura e produção de palavras escritas" (Soares, 2018, p. 36), muitas pessoas têm como primeira referência a aprendizagem do sistema alfabético-ortográfico latino para a escrita e a leitura da língua portuguesa. Contudo, tal ferramenta de escrita, apesar de possibilitar a alfabetização das pessoas surdas em língua portuguesa, entendida neste artigo como segunda língua desses indivíduos, não oportuniza a alfabetização em Libras - assumida neste texto como língua primeira dos surdos.

As pessoas surdas aprendem a sinalizar (falar) em Libras naturalmente, desde que inseridas em um ambiente em que o uso cotidiano dessa língua ocorra livremente. Destarte, a aquisição da Libras por crianças surdas não demanda um ensino formalizado, mas a sua inserção em uma comunidade surda sinalizadora (Quadros, 1997). Logo, aquisição da língua — seja ela oral ou de sinais — não é a mesma coisa que alfabetização. Isso posto, dizer que a criança ou o adulto que tem competência linguística em Libras é alfabetizado em Libras seria um equívoco conceitual.

Do que se trata, então, a alfabetização em Libras defendida neste artigo? Trata-se da aprendizagem de um sistema de escrita que seja capaz de registar desde as menores unidades constitutivas do léxico da Libras até a sua morfologia e a sua sintaxe espacial, possibilitando a leitura e a escrita de textos diversos, sem a necessidade de tradução para uma língua oral. Neste artigo, assume-se o sistema SignWriting - sistema ortográfico para a escrita e a leitura de qualquer língua de sinais - como instrumento capaz de possibilitar às pessoas surdas e não surdas a aprendizagem da dimensão escrita da Libras. Assumir isso acarreta dizer que, para o autor deste texto, a Libras não é ágrafa, a despeito do que argumentam outros autores, e que a alfabetização em Libras precisa ocupar os espaços escolares em que estudantes surdos estejam inseridos.

A escolha pelo sistema SignWriting neste artigo — em detrimento de outros sistemas de escrita propostos para o registro escrito das línguas de sinais - para tratar da alfabetização de surdos em Libras não é aleatória. Além de ser um dos sistemas de escrita de línguas de sinais "que está mais em evidência ultimamente", Stumpf $(2016$, p. 83, 114) explica:

[...] os linguistas que trabalham com língua de sinais concordam, em sua grande maioria, que ele é o único, dentre os já criados, que se presta para a comunicação entre pessoas, haja vista que o sistema de Stokoe, assim como outros, tem o objetivo de anotar a língua para pesquisa, sendo muito limitados e focados na notação do sinal, não do contexto.

Entendendo a escrita segmental como um modo de representação da língua falada/sinalizada - ciente das suas características arbitrárias, nem sempre biunívocas e por vezes opacas - cabe agora apresentar, mesmo que brevemente, como os sistemas alfabético-ortográficos latino e o SignWriting funcionam em relação ao par linguístico em análise - língua portuguesa e Libras. Observe os exemplos na Figura 1: 


\begin{tabular}{|c|c|}
\hline $\begin{array}{c}\text { Transcrição fonética } \\
\text { da palavra em português }\end{array}$ & $\begin{array}{c}\text { Escrita alfabética } \\
\text { da palavra em português }\end{array}$ \\
\hline $\begin{array}{c}\text { [kãma] } \\
\text { Fonte: Soares }(2018, \text { p. 308). }\end{array}$ & $\begin{array}{c}\text { cama } \\
\text { Fonte: Soares }(2018, \text { p. 308). }\end{array}$ \\
\hline Imagem do sinal em Libras & $\begin{array}{c}\text { Escrita em SignWrting } \\
\text { do sinal em Libras }\end{array}$ \\
\hline Fonte: Adaptado de Capovilla et al. (2009, p. 484). & Fonte: Adaptado de Capovilla et al. (2009, p. 484). \\
\hline
\end{tabular}

Figura 1 - Representação da/do palavra/sinal CAMA em escrita alfabética e em SignWriting. Elaboração do autor.

Soares (2018, p. 46) explica que "ao contrário das escritas logográficas ou ideográficas, que grafam o significado - o conteúdo semântico da fala -, a escrita alfabética grafa os significantes - os sons da fala -, decompondo-os em suas unidades mínimas, os fonemas [...]”. O sistema SignWriting funciona na mesma lógica dos sistemas de escrita alfabética, pois registra as unidades corpóreo-visuais mínimas que constituem um sinal, quais sejam: configuração da mão, locação, movimento, orientação da palma e expressão corpóreo-facial. Tais constituintes podem ser mais bem visualizados no esquema da Figura 2, tomando o mesmo exemplo previamente apresentado no Figura 1:

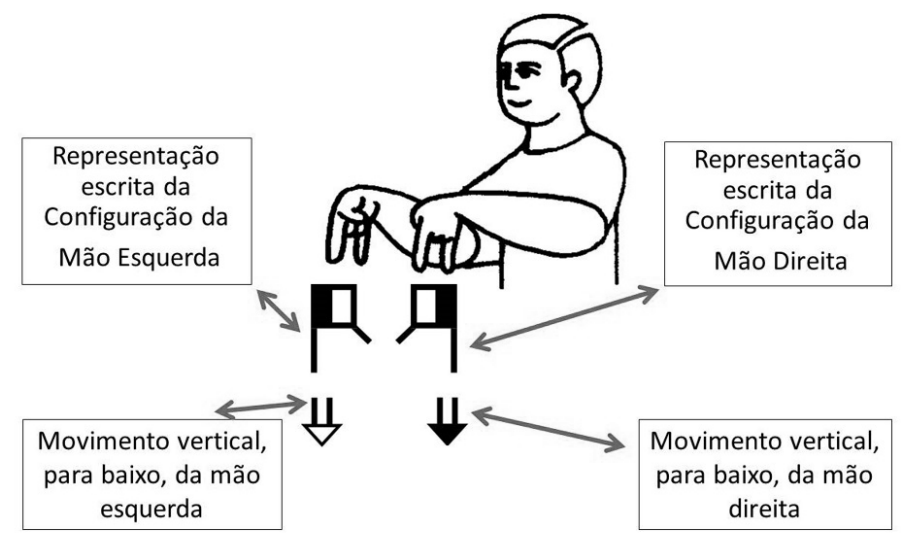

Figura 2 - Apresentação das unidades mínimas do sinal em SignWriting.

Fonte: Adaptação de Capovilla et al. (2009, p. 484).

Elaboração do autor. 
Percebe-se que na Figura 2 o componente expressão corpóreo-facial (também chamado de expressão não manual) não está evidenciado na escrita do sinal ( $\left.\begin{array}{l}\text { P } \\ \forall \\ \forall\end{array}\right)$ CAMA. Isso ocorre porque, nesse caso, a expressão corpóreo-facial é neutra, dispensando, portanto, seu registro escrito. Quanto à unidade mínima da orientação da palma, esta pode ser percebida na escrita do sinal, pois cada mão está grafada em duas cores ( $\left.\begin{array}{ll}\mathbf{R} & \boldsymbol{q}\end{array}\right)$ - metade preta e metade branca —, sendo essa uma regra ortográfica do sistema SignWriting para indicar que as palmas das mãos estão em posição ipsilateral.

O que se pretende com essa exposição básica e epidérmica do SignWriting não é fazer uma digressão sem sentido, mas demonstrar que a Libras - como uma língua de modalidade corpóreo-visual - não se faz contemplada em um formato de escrita baseado no alfabeto-ortográfico latino. Cabe ressaltar que o sistema SignWriting apresenta a mesma natureza funcional dos sistemas de escrita alfabética, mas não seria adequado chamá-lo de sistema alfabético por pelo menos duas razões: primeiramente pela etimologia da palavra alfabeto e ao sentido que ela remete; depois porque o léxico das línguas de sinais e o próprio sistema SignWriting não funciona com base em letras. Seria mais adequado dizer que o SignWriting é um sistema de escrita segmental sublexical para línguas sinalizadas, com natureza funcional semelhante aos sistemas de escrita alfabética das línguas orais.

Pesquisa conduzida por Stumpf (2005) evidencia fortemente que a alfabetização ${ }^{1}$ de crianças surdas em Libras mediada pelo sistema de escrita SignWriting proporciona a esses indivíduos a aquisição da escrita de uma forma que lhes faz verdadeiro sentido. Em seu estudo, Stumpf (2005, p. 266, grifo meu) conclui:

A escrita precisa ser uma atividade significativa para a criança. Na presente pesquisa, as crianças podem escrever baseadas em sua compreensão da língua de sinais não necessitando da intermediação da língua oral. Observamos também que, no ambiente de uma classe de surdos, onde o professor e os colegas se comunicam em língua de sinais, elas efetivamente tentam escrever os sinais quando estimuladas a isso.

Estimular o registro dos sinais por meio do sistema SignWriting possibilita à criança surda a apreensão da escrita como uma representação da língua sinalizada, pois é uma grafia que evoca todo o conhecimento linguístico da Libras que o aprendiz dispõe, sem a necessidade de tradução/interferência para/da língua portuguesa. Ao escrever nesse sistema, as crianças surdas "aprendem a estabelecer correspondência entre os sinais e os símbolos do SignWriting”. Stumpf (2005, p. 106) argumenta ainda:

A decomposição do sinal escrito, relacionando os diferentes elementos gráficos mínimos, representados pela escrita, com os elementos fonológicos, morfológi-

1 Nesta seção, o termo alfabetização está recebendo uma extensão semântica, pois, como pontuado no corpo do texto, a escrita pelo sistema SignWriting não é propriamente alfabética. 
cos, sintáticos e semântico-pragmáticos da língua sinalizada permite ao aprendiz compreender o processo e tentar construir sua própria escrita.

Decompor o que está sendo escrito, compreender o processo de escrita e construir sua própria escrita autonomamente são atividades que requerem consciência metalinguística da língua na qual se está sendo alfabetizado. Essa consciência metalinguística não se restringe à consciência fonêmica, mas estende-se também aos outros níveis da língua. Nesta seção, a ênfase no potencial metalinguístico do SignWriting não significa que se espera que os alfabetizadores de surdos devam tomar como fim do processo de alfabetização o domínio, por parte dos alunos surdos, da segmentação sublexical das unidades linguísticas da Libras. Aqui, intenta-se apenas dar destaque às especificidades e potencialidades funcionais do SignWriting em contraste com o sistema alfabético-ortográfico latino.

Assume-se, neste artigo, o entendimento de que todo trabalho educativo formal com a linguagem, escrita ou sinalizada/falada, é permeado de relações ideológicas de poder. Nesse sentido, entende-se que a língua é utilizada socialmente não só para a comunicação, mas também como instrumento de dominação, exclusão e estratificação social. Por isso, ao se alfabetizar crianças surdas para além do alfa e do beta, quer seja Libras, quer em língua portuguesa, deve-se objetivar instrumentalizá-las para que (Freire, 2016, p. 102) “diminuam as desvantagens na luta pela vida" e "ganhem um instrumento fundamental para a briga necessária contra as injustiças e as discriminações de que são alvo".

\section{ALFABETIZAÇÃO DE SURDOS EM LÍNGUA PORTUGUESA}

Este texto não nega que a escrita da língua portuguesa materializa no papel, entre outras coisas, uma face sonora da língua que é evocada no momento da produção escrita e da leitura de um texto. Contudo, cabe esclarecer que, ao passo que a criança não surda, à medida que se vai apropriando da escrita da língua portuguesa, começa a perceber a lógica do sistema alfabético e a segmentar as palavras adquirindo consciência da dimensão metalinguística fonêmica da escrita, com crianças surdas em processo de alfabetização nas línguas orais isso geralmente ${ }^{2}$ não ocorre. Entre outros fatores, esse processo não ocorre porque a escrita das línguas orais registra de forma gráfica (Soares, 2018, p. 28, grifo meu) "a representação visual da cadeia sonora da fala", cadeia sonora esta inacessível à pessoa surda pela obviedade da sua condição sensorial — ser surda.

Portanto, resta prejudicada qualquer abordagem de ensino da língua portuguesa escrita para surdos que tome como base o paradigma fonológico. Cardoso-Martins e Corrêa (2008, p. 279) explicam que tal paradigma

2 Existem diferentes graus de perda auditiva. Algumas pessoas surdas são oralizadas, ou seja, falam a língua oral do seu país de origem. Em alguns desses casos, tais sujeitos apresentam um conhecimento significativo da língua oral e utilizam-na com desenvoltura, cotidianamente, em seus contatos com pessoas não surdas. 
[...] baseia-se no pressuposto de que a principal tarefa da criança ao aprender a ler e escrever consiste em compreender que as letras representam sons na pronúncia das palavras. Como resultado, esse paradigma tem estimulado estudos sobre a relação entre o desenvolvimento do conhecimento das correspondências letra-som e da consciência fonológica, por um lado, e o desenvolvimento da escrita, por outro lado.

A adoção de uma abordagem de alfabetização de surdos em língua portuguesa, que toma como referência o paradigma fonológico, tem sido contraproducente e desastrosa para os aprendizes surdos. Nesse sentido, Pereira (2012, p. 239) defende:

[...] é necessário que se mude a concepção de escrita que ainda predomina na maior parte das instituições que atendem surdos no Brasil. Continua a prevalecer uma preocupação com a alfabetização, ou seja, com o ensino das letras, sua combinação em vocábulos, codificação e decodificação dos mesmos, sendo atribuída pouca ou nenhuma importância aos usos da escrita enquanto práticas sociais mais amplas (letramento). Como resultado disso, muitos alunos surdos, embora identifiquem significados isolados de palavras, e sejam capazes de usar as estruturas frasais trabalhadas, não conseguem fazer uso efetivo da língua [...].

De fato, conceber a alfabetização de surdos para além do alfa e do beta é não apenas necessário, mas urgente. Porém, certos aspectos precisam ficar muito claros quando se pensa a alfabetização de surdos em língua portuguesa. Em primeiro lugar, professores, educadores e alfabetizadores precisam ter a clareza de que a língua portuguesa não é a língua de referência para a construção do conhecimento de mundo e de organização do pensamento do aluno surdo, mas sim a Libras. Entender e aceitar esse fato é princípio básico, pois essa é uma diferença radical entre o aluno surdo e o aluno não surdo, que acarreta implicações profundas no processo de ensino e aprendizagem nas aulas de língua portuguesa.

Atualmente, no modelo educacional inclusivo brasileiro, crianças surdas e não surdas frequentam juntas as aulas de todas as disciplinas, até mesmo as de língua portuguesa. Geralmente, durante a leitura de um texto, por exemplo, o professor de português não precisa trabalhar o significado das palavras, exceto se houver alguma palavra que foge ao vocabulário cotidiano de seus alunos. O docente, corretamente, parte do pressuposto de que todos ali são falantes nativos do português e é demasiado desnecessário trabalhar os aspectos semânticos lexicais do texto. Contudo, quando há alunos surdos na sala de aula, esse pressuposto está equivocado, pois é muito provável que esses discentes desconheçam o significado de quase todas as palavras do texto.

O segundo aspecto crucial é que, a menos que o professor alfabetizador tenha domínio linguístico pleno da Libras e da língua portuguesa, a alfabetização do aluno surdo não terá o êxito almejado. Isso ocorre porque o aluno surdo, ao aprender a língua portuguesa escrita, depende que a instrução formal chegue até ele por meio da língua que melhor organiza seu pensamento intelectual, nesse caso a Libras. Será preciso que o alfabetizador recorra com frequência a semelhanças e contrastes entre os aspectos linguísticos formais, discursivos e pragmáticos de uma língua e de outra. 
Tome-se o mesmo exemplo da sala de aula inclusiva, com alunos surdos e não surdos, ainda na mesma sequência didática da leitura de um texto. Suponha-se que o professor alfabetizador, mesmo não sabendo a Libras, que é uma realidade muito comum nas escolas brasileiras, sugira aos alunos surdos que busquem em dicionários, impressos ou virtuais em Libras, os significados para cada palavra do texto impresso em língua portuguesa. Essa seria uma estratégia que, a princípio, poderia dar certo. Contudo, "a principal dificuldade dos surdos, quando escrevem uma língua oral" - guardadas as especificidades idiossincráticas da polissemia "não é o léxico e sim a sintaxe" (Stumpf, 2005, p. 44).

O ponto ao qual se quer chegar aqui é: Como o professor alfabetizador, que não tem domínio linguístico pleno da Libras e da língua portuguesa, vai explicar para o aprendiz surdo palavras funcionais do texto em língua portuguesa como "de/da" e "no/na", por exemplo? O professor com domínio linguístico pleno da Libras e da língua portuguesa, sabendo que essas palavras funcionais não acham correspondentes na Libras e que irão apresentar valor semântico diferenciado a depender do contexto sintático em que ocorrem, entende que seria inútil propor aos discentes surdos a busca por significados em dicionários. A alternativa mais razoável e eficiente seria a intervenção consciente do professor que, por meio do ensino direto e formal, explicasse as possibilidades de ocorrências dessas palavras funcionais em determinados contextos sintáticos, expondo seus respectivos valores semânticos em cada caso.

Um terceiro ponto a ser considerado pelos professores alfabetizadores de surdos é que o ensino da escrita em língua portuguesa deve partir da leitura de textos reais produzidos nessa língua. Visto que o português na modalidade oral não é apreendido pelos surdos, os textos escritos serão, para esses sujeitos, a principal via de acesso ao conteúdo dessa língua. Não há que se falar, contudo, em textos produzidos especificamente para o ensino de leitores surdos. A abordagem de ensino deve sim ser diferenciada, pelos motivos que vêm sendo apresentados no decorrer deste artigo, mas não seria acertado caricaturar o uso da escrita ou de produções culturais, visando adaptá-las a aprendizes surdos.

Karnopp (2012), relatando alguns dos depoimentos colhidos em pesquisa com universitários surdos, explica que para esses acadêmicos a leitura de obras inteiras foi uma novidade vivenciada a partir do ingresso na graduação. Segundo os universitários, durante a educação básica, as leituras propostas consistiam em pequenos textos de jornais e revistas. Os professores evitavam propor atividades de leitura e escrita partindo da premissa de que os surdos têm extrema dificuldade de ler e escrever ou que eles não gostam dessas atividades. A autora continua seu relato:

Isabel, 21 anos, uma das universitárias, declarou ainda que, na turma em que estudava, os alunos questionaram o trabalho do professor, perguntando: "Por que não lemos livros agora que estamos no Ensino Médio?” E o professor respondeu que tal atividade era de extrema dificuldade para alunos surdos e eu eles precisavam estudar primeiro o vocabulário, a gramática e a estruturação das frases em pequenos textos para depois realizarem a leitura de livros. Contrariados com a resposta do professor, foram em horário extraclasse até a biblioteca 
para escolher alguns livros. Lá chegando, o bibliotecário lhes ofereceu somente livros fininhos, infantilizados, recomendando que aqueles eram mais fáceis para eles. Os livros então indicados não foram lidos, pois o tema não era de interesse dos alunos e, ao mesmo tempo, eles não queriam sair da biblioteca com um livro indicado para a faixa etária diferente daquela em que se encontravam. Temiam que alguém questionasse a utilização de um livro infantil para um público adulto, jovem como eles. Retornaram e seguiram as aulas do Ensino Médio sem a leitura de um único livro. (Karnopp, 2012, p. 154-155)

Esse relato ilustra como a preocupação, ainda que bem intencionada, de alguns professores em adaptar o conteúdo das leituras que se disponibiliza aos discentes surdos pode limitar e inibir a busca desses alunos por obras escritas em língua portuguesa. A exposição dos alunos surdos a textos de temáticas diversificadas pode ser uma fonte rica de ampliação do repertório vocabular e das demais estruturas de superfície presentes nos textos. Ademais, muito do conhecimento historicamente acumulado só pode ser acessado por meio da leitura de obras escritas, muitas delas disponíveis aos surdos apenas em língua portuguesa.

\section{ALFABETIZAR EM LIBRAS E EM PORTUGUÊS: PONTOS PROBLEMÁTICOS}

A problemática que se coloca com mais força sobre a alfabetização dos surdos em SignWriting é o uso social dessa escrita. Os estudos até agora empreendidos não deixam dúvidas de que "o conteúdo escrito em $S S W$ [sistema SignWriting] segue a organização do pensamento e a estrutura gramatical da Libras sem que haja interferência de qualquer língua falada" (Stumpf, 2016, p. 87), porém a escrita que predomina na prática social dos cidadãos brasileiros é luso-grafocêntrica, tendo o sistema alfabético-ortográfico latino como hegemônico. Logo, ainda que as crianças surdas sejam alfabetizadas em Libras, quais seriam as práticas sociais de leitura e escrita que teriam como requisito o uso do sistema SignWriting? Seria uma escrita restrita apenas ao ambiente escolar e acadêmico? Em caso afirmativo, quais disciplinas adotariam o SignWriting como escrita durante as aulas, apenas a disciplina Libras?

Esses questionamentos não são tão simples de serem dirimidos. Muito do que se pretende em relação à alfabetização de surdos em Libras, mediante o uso do SignWriting, depende de uma política linguística consistente que sistematize pelo menos quatro medidas: primeiro, que o SignWriting seja definido como escrita oficial da Libras; segundo, que a formação de todos os professores de Libras inclua o ensino obrigatório do SignWriting para esses licenciandos; terceiro, que na alfabetização de crianças surdas em Libras adote-se o SignWriting como sistema de 
escrita: ${ }^{3}$ quarto, que haja fomento financeiro à produção e à circulação de materiais didáticos e paradidáticos escritos em SignWriting.

Não é razoável, porém, confundir o uso social da escrita com uma visão utilitarista dela. Isso é especialmente preocupante no caso da alfabetização de crianças surdas em Libras pelo SignWriting, pois tal utilitarismo curto pode limitar a oportunidade de essas crianças terem contato com uma forma de escrita que lhes proporcione uma interação direta entre o registro escrito e sua língua natural. Em sua tese, Stumpf (2005) relata que, durante seu estágio doutoral sanduíche na França, alguns professores e alunos não recepcionaram bem a proposta de alfabetização em Língua de Sinais Francesa (LSF) por meio do SignWriting por acreditarem que a prioridade deveria ser a alfabetização em francês escrito, apenas. Como se expressou certo aluno, "a escrita de LSF não serve para o trabalho no futuro" (Stumpf, 2005, p. 200).

Sobre a alfabetização de surdos em português, são muitas as problemáticas e as polêmicas que poderiam figurar neste tópico, mas apenas uma será tomada - o fator psicolinguístico da continuidade comunicativa. Capovilla et al. (2006, p. 1.942) explicam o fenômeno da continuidade nos seguintes termos:

$\mathrm{Na}$ criança ouvinte e falante, há uma continuidade entre três contextos comunicativos básicos: A comunicação transitória consigo mesma (i.e., o pensar), a comunicação transitória com outrem na relação face a face (i.e., o falar), e a comunicação perene na relação remota e mediada (i.e., o escrever). Com isto, todo o seu processamento lingüístico $[$ sic $]$ pode concentrar-se na palavra falada de uma mesma língua: Para pensar, comunicar-se e escrever, ela pode fazer uso das mesmas palavras de sua própria língua falada primária. Para essa criança há uma compatibilidade entre os sistemas de representação linguística primária (i.e., língua falada) e secundária (i.e., a língua escrita alfabética).

É possível que ocorra com as crianças surdas uma ruptura do fator psicolinguístico da continuidade comunicativa durante a alfabetização em língua portuguesa. A criança surda pensa em Libras, estabelece suas relações face a face em Libras com interlocutores falantes da Libras, mas na hora de escrever são instruídas a fazê-lo em língua portuguesa. $\mathrm{O}$ resultado dessa descontinuidade é facilmente perceptível na organização sintática dos textos produzidos por surdos alfabetizados em língua portuguesa, que na verdade materializam no papel um reflexo do pensamento sintático da pessoa surda originado/organizado em Libras. Sobre essa característica dos textos escritos por pessoas surdas, Perlin (2003, p. 53) explica que "a escrita dos surdos será sempre na língua de fronteira, não em português política e espistemologicamente correto como escrevem os ouvintes".

3 O Relatório sobre a politica linguística de educação bilingue - Lingua Brasileira de Sinais e lingua portuguesa defende o "letramento visual dos surdos em Escrita de Sinais"(Brasil, 2014), mas não define qual sistema de escrita de sinais deveria ser adotado durante o processo de alfabetização na primeira língua das crianças surdas. 
Em relação à escrita dos surdos em língua portuguesa, muitas vezes parece passar despercebido que não se trata da conversão contínua de uma língua sinalizada para uma escrita sinalizada - como ocorre quando se escreve e se lê em SignWriting —, mas da tradução de um pensamento gerado/organizado em Libras — uma língua cuja modalidade de produção e de recepção é corpóreo-visual - para uma escrita que funciona dentro dos moldes estruturais da língua portuguesa, de modalidade oral-auditiva. Não se trata, portanto, de pensar e escrever na mesma língua, mas realmente de traduzir da Libras (língua de partida) para a língua portuguesa (língua de chegada), de modo que torne o texto de chegada inteligível, preciso, coerente e coeso, tanto para o escritor quanto para o leitor. Não é de surpreender que Perlin (2015, p. 57), referindo-se à produção escrita de pessoas surdas em língua portuguesa, conclua: "não há que se exigir do surdo uma construção simbólica tão natural como a do ouvinte".

Com essa argumentação, não se intenta negar a importância da língua portuguesa para a inserção e a participação dos surdos nas esferas sociais e trânsito e acesso a estratos sociais mais elevados. Esse ponto é um truísmo que já não carece de debate. Muito menos dizer que de nada adianta ensinar aos surdos a escrita do português e suas minúcias ortográficas. Intenciona-se, isto sim, alertar os docentes de que as especificidades dos alfabetizandos surdos impõe aos alfabetizadores a necessidade de aderir a abordagens de ensino que levem em conta o desgaste cognitivo, demandado desses estudantes no processo de aprendizagem da escrita da língua portuguesa.

\section{CONSIDERAÇÕES FINAIS}

Do acúmulo de discussões tecidas nas seções pregressas deste artigo, foi possível apresentar duas propostas de alfabetização para surdos que não são excludentes, nem dicotômicas, mas igualmente necessárias. Importa frisar aqui que a alfabetização em Libras, no cenário atual da educação de surdos no Brasil, é a modalidade de alfabetização de surdos mais vulnerável e opacizada nos documentos parametrizadores da educação nacional. Em contrapartida, a alfabetização em língua portuguesa já tem amparo legal e políticas educacionais que buscam assegurar esse direito aos surdos - com muitos percalços, lacunas e pouco conhecimento teórico, o que resulta em um processo de ensino ineficiente e mantenedor de assimetrias de aprendizagem.

Das premissas para os professores alfabetizadores de surdos em língua portuguesa, apresentadas aqui na terceira seção, depreende-se que a formação de professores com conhecimento aprofundado acerca do par linguístico Libras/português é fio condutor para que o ensino formal da língua portuguesa escrita para surdos logre êxito, no sentido de conduzir os discentes surdos ao domínio satisfatório da escrita da língua majoritária nacional. A despeito do modelo educacional que se adote - educação inclusiva: escola comum frequentada por alunos surdos e não surdos; ou educação bilíngue, escola modelada especificamente para atender alunos surdos tendo a Libras como língua de instrução em todos os momentos de ensino e a língua portuguesa como segunda língua na modalidade escrita -, atender à 
demanda por formação de professores com a habilitação profissional específica para suprir as necessidades que a educação de surdos impõe deve ser prioridade.

Reconhece-se que a sugestão de recorrer às políticas linguísticas como caminho delineador das possíveis soluções para as problemáticas que subjazem a alfabetização de surdos em Libras, por meio do sistema SignWriting, apresentadas com maior vagar na quarta seção deste trabalho, pode soar ao leitor como imposição e corporativismo de um autor que foi convertido ao suttonismo. ${ }^{4}$ Ainda assim - admitidas as necessárias e saudáveis posições contrárias no cenário atual, em que vicejam pesquisas e novas propostas de sistemas de escrita de línguas de sinais no âmbito acadêmico, e o direito do leitor de construir seu próprio juízo de valor em relação a este texto - o anseio maior é de que a alfabetização de surdos em Libras esteja munida de concretude e de sistematizações orientadoras, que balizem e assegurem a sua implementação nas escolas brasileiras em que há alunos surdos.

Por derradeiro, almeja-se que as reflexões, discussões e proposição apresentadas neste trabalho induzam leitores e pesquisadores, surdos e não surdos, a se inquietarem ante a temática proposta. É certo que ainda há uma carência de pesquisas - especialmente os estudos longitudinais sobre a aprendizagem do SingWriting por crianças surdas e sobre o ensino sistematizado do português escrito para surdos que deem o suporte científico necessário às práticas pedagógicas dos alfabetizadores. Infelizmente, essa carência — não ausência —, embora não licencie, pode favorecer o improviso e a inércia escolar no que respeita à alfabetização de surdos no Brasil.

\section{REFERÊNCIAS}

ALMEIDA, M. L. G. A importância da escrita de sinais junto com o ensino da Libras. 2015. Dissertação (Mestrado Profissional em Ensino em Ciência de Saúde) - Universidade Federal de São Paulo, São Paulo, 2015.

BARRETO, M.; BARRETO, R.Escrita de sinais sem mistérios. 2. ed. rev. atual. ampl. Salvador: Libras Escrita, 2015.

BARTH, C. Construção da leitura/escrita em língua de sinais de crianças surdas em ambientes digitais. 2008.141 fls. Dissertação (Mestrado em Educação) - Universidade Federal do Rio Grande do Sul, Porto Alegre, 2008.

BÓZOLI, D. M. F. Um estudo sobre o aprendizado de conteúdos escolares por meio da escrita de sinais em escola bilíngue para surdos. 2015. 188 fls. Dissertação (Mestrado em Educação) — Universidade Estadual de Maringá, Maringá, 2015.

BRASIL. Relatório sobre a política linguística de Educação Bilíngue - Língua Brasileira de Sinais e Língua Portuguesa. Brasília, DF: MEC/SECADI, 2014. Disponível em: http://www.bibliotecadigital.unicamp.br/document/?down=56513. Acessado em: 23 maio 2019.

4 Referência à vertente de pesquisadores, professores e demais indivíduos que defendem e/ ou acreditam que o sistema SignWriting, criado por Valerie Sutton em 1974, seja a via mais adequada para a alfabetização de surdos em Libras e para a leitura e escrita dessa língua. 
CAPOVILLA, F. C. et al. A escrita visual direta de sinais Sign Writing e seu lugar na educação da criança surda. In: CAPOVILLA, F. C.; RAPHAEL, W. D. Dicionário enciclopédico ilustrado trilíngue da Língua Brasileira de Sinais - volume II: sinais de M a Z. 3. ed. São Paulo: Edusp, 2006. p. 1.491-1.496.

CAPOVILLA, F. C.; RAPHAEL, W. D.; MAURÍCIO, A. C. L. Novo Deit-Libras: dicionário enciclopédico ilustrado trilíngue da Língua de Sinais Brasileira (Libras) baseado em linguística e neurociências cognitivas. Volume I: sinais de A a H. São Paulo: Edusp; Inep; CNPq, 2009.

CARDOSO-MARTINS, C.; CORRÊA, M.F.O desenvolvimento da escrita nos anos pré-escolares: questões acerca do estágio silábico. Psicologia:Teoria e Pesquisa, Brasília, DF, v. 24, n. 3, p. 279-286, 2008. https://doi.org/10.1590/s0102-37722008000300003 COSTA, D. A. F. A apropriação da escrita por crianças e adolescentes surdos: interação entre fatores contextuais, L1 e L2 na busca de um bilinguismo funcional. 2001. Tese (Doutorado em Linguística) - Universidade Federal de Minas Gerais, Belo Horizonte, 2001.

DALLAN, M. S. S. Análise discursiva dos estudos surdos em educação: a questão da escrita de sinais. 2012. Dissertação (Mestrado em Educação) - Universidade de São Francisco, Itatiba, 2012.

DECHANDT-BROCHADO, S. M. A apropriação da escrita por crianças surdas usuárias da Língua de Sinais Brasileira. 2003. 439 fls. Tese (Doutorado em Letras) - Universidade Estadual Paulista "Júlio de Mesquita Filho", Assis, 2003.

DECHANDT-BROCHADO, S. M. A apropriação da escrita por crianças surdas. In: QUADROS, R. M. (org.). Estudos surdos I. Petrópolis: Arara Azul, 2006. p. 284-322.

DENARDI, R. M. $\boldsymbol{A} \boldsymbol{G} \boldsymbol{A}$-Sing: animador de gestos aplicado à língua de sinais. 2006. 82 fls. Dissertação (Mestrado em Ciência da Computação) - Universidade Federal do Rio Grande do Sul, Porto Alegre, 2006.

FINAU, R. O processo de formação de interlíngua na aquisição de língua portuguesa por surdos e as categorias de tempo e aspecto. In: SALLES, H.M.M. L. (org.). Bilinguismo dos surdos: questões linguísticas e educacionais. Goiânia: Cânone Editorial, 2007. p. 159-190.

FREIRE, P. Professora sim, tia não: cartas a quem ousa ensinar. São Paulo: Paz e Terra, 2016.

GESUELI, Z. M. A criança não ouvinte e a aquisição da escrita. 1998. 209 fls. Dissertação (Mestrado em Linguística) - Universidade Estadual de Campinas, Campinas, 1988.

GESUELI, Z. M. A escrita como fenômeno visual nas práticas discursivas de alunos surdos. In: LODI, A. C. B.; MÉLO, A. D. B.; FERNANDES, E. (orgs.). Letramento, bilinguismo e educação de surdos. Porto Alegre: Mediação, 2012. p. 173-186.

KARNOPP, L. B. Práticas de leitura e escrita entre os surdos. In: LODI, A. C. B.; MÉLO, A. D. B.; FERNANDES, E. (orgs.). Letramento, bilinguismo e educação de surdos. Porto Alegre: Mediação, 2012. p. 153-172. 
KARNOPP, L. B.; PEREIRA, M. C. C. Concepção de leitura e de escrita na educação de surdos. In: LODI, A. C. B.; MÉLO, A.D. B.; FERNANDES, E. (orgs.). Letramento, bilinguismo e educação de surdos. Porto Alegre: Mediação, 2012. p. 125-134.

KOGUT, M. K. As descrições imagéticas na transcrição e leitura de um texto em SignWriting. 2015. 161 fls. Dissertação (Mestrado em Linguística) — Universidade Federal de Santa Catarina, Florianópolis, 2015.

LABORIT, E. O grito da gaivota. Translation of Ângela Sarmento. Lisboa: Caminho, 2000. Original Title: Le cri de la mouete.

LOUREIRO, C. B. C. Processo de apropriação da escrita da língua de sinais e escrita da língua portuguesa: informática na educação. 2004. 150 fls. Dissertação (Mestrado em Educação) - Universidade Federal do Rio Grande do Sul, Porto Alegre, 2004.

NOBRE, R. S. Processo de grafia da língua de sinais: uma análise fono-morfológica da escrita em Sign Writing. 2011. 203 fls. Dissertação (Mestrado em Linguística) Universidade Federal de Santa Catarina, Florianópolis, 2011.

PEREIRA, M. C. C. Papel da língua de sinais na aquisição da escrita por estudantes surdos. In: LODI, A. C. B.; MÉLO, A. D. B.; FERNANDES, E. (orgs.). Letramento, bilinguismo e educação de surdos. Porto Alegre: Mediação, 2012. p. 235-246.

PERLIN, G.T.T. O ser e o estar sendo surdos: alteridade, diferença e identidade. 2003. 156 fls. Tese (Doutorado em Educação) - Universidade Federal do Rio Grande do Sul, Porto Alegre, 2003.

PERLIN, G. T.T. Identidades surdas. In: SKLIAR, C. (org.). A surdez: um olhar sobre as diferenças. 7. ed. Porto Alegre: Mediação, 2015. p. 51-73.

PIRES, L. C.; LOPES, R. E. V. A aquisição da flexão em português escrito por sinalizantes surdos: uma reflexão inicial sobre educação bilíngue. In: SALLES, H. M. M. L. (org.). Bilinguismo dos surdos: questões linguísticas e educacionais. Goiânia: Cânone Editorial, 2007. p. 17-48.

QUADROS, R. M. Educação de surdos: a aquisição da linguagem. Porto Alegre: Artmed, 1997.

QUADROS, R.M.; SCHMIEDT, M. L.P. Ideias para ensinar português para alunos surdos. Brasília, DF: MEC/SEESP, 2006.

RIBEIRO, V. P. Ensino de língua portuguesa para surdos: percepções de professores sobre adaptação curricular em escolas inclusivas. Curitiba: Prismas, 2013.

SALLES, H. M. M. L.; FAULSTICH, E.; CARVALHO, O. L.; RAMOS, A. A. L. Ensino de língua portuguesa para surdos: caminhos para a prática pedagógica. Brasília, DF: MEC/SEESP, 2004a. v. 1.

SALLES, H. M. M. L.; FAULSTICH, E.; CARVALHO, O. L.; RAMOS, A. A. L. Ensino de língua portuguesa para surdos: caminhos para a prática pedagógica. Brasília, DF: MEC/SEESP, 2004b. v. 2.

SALLES, H. M. M. L.; SALLES, P. S. B. A.; CHAN-VIANA, A. C. Formulação de inferências e propriedades da interlíngua dos surdos na aquisição do português (escrito). 
In: SALLES, H. M. M. L. (org.). Bilinguismo dos surdos: questões linguísticas e educacionais. Goiânia: Cânone Editorial, 2007. p. 97-118.

SILVA, E. V. L. Narrativas de professores surdos sobre a escrita de sinais. 2013.113 fls. Dissertação (Mestrado em Educação) - Universidade Federal do Rio Grande do Sul, Porto Alegre, 2013.

SILVA, F. I. Analisando o processo de leitura de uma possível escrita da Língua Brasileira de Sinais: Sign Writing. 2009. 114 fls. Dissertação (Mestrado em Educação) - Universidade Federal de Santa Catarina, Florianópolis, 2009.

SOARES, M. Alfabetização: a questão dos métodos. São Paulo: Contexto, 2018.

STUMPF, M. R. Aprendizagem de escrita de língua de sinais pelo sistema Sign Writing: língua de sinais no papel e no computador. 2005. 330 fls. Tese (Doutorado em Informática na Educação) - Universidade Federal do Rio Grande do Sul, Porto Alegre, 2005.

STUMPF, M.R. O estado da arte da escrita de língua de sinais pelo sistema SignWriting: uma meta-análise. In: BIDARRA, J.; MARTINS, T. A.; SEIDE, M. S. (orgs.). Entre a Libras e o português: desafios face ao bilinguismo. Cascavel: EDUNIOSTE; Londrina: EDUEL, 2016. p. 83-116.

WANDERLEY, D. C. Aspectos da leitura e escrita de sinais: estudos de caso com alunos surdos da educação básica e de universitários surdos e ouvintes. 2012.192 fls. Dissertação (Mestrado em Linguística) - Universidade Federal de Santa Catarina, Florianópolis, 2012.

ZAPPE, C. T. Escrita da língua de sinais em comunidades do Orkut: marcador cultural na educação de surdos. 2010.67 fls. Dissertação (Mestrado em Educação) Universidade Federal de Santa Maria, Santa Maria, 2010.

\section{SOBRE O AUTOR}

IsaAC Figueredo de Freitas é doutorando em linguística pela Universidade Federal de Santa Catarina (UFSC). Professor na Universidade Federal do Vale do São Francisco (UNIVASF).

E-mail: isaacfreitas123@hotmail.com

Recebido em 4 de junbo de 2019

Aprovado em 10 de fevereiro de 2020 